\title{
On the Imagery Creating by Music Catalogue
}

\author{
Qiong Xie \\ Publishing and Art Design College \\ University of Shanghai for Science and Technology \\ Shanghai, China
}

\author{
Wei Wang \\ Publishing and Art Design College \\ University of Shanghai for Science and Technology \\ Shanghai, China
}

\begin{abstract}
Music Catalogue is one of the important parts of the present worldwide art performance activities, existing widely among all the music performance types. Music belong to the Art of "Listening", while Brochure Design belongs to the Art of "Vision", they both have some points in commons, but need the designer to transform using a proper method. In this thesis, we are researching on how to transform the music sense into a proper imagery to audience by a visualization method, making the audience can feel the performance atmosphere when they looked the brochures. The research technique is mainly to create a musical circumstance by using of the imaging musical symbols, musical images, and also the visual performance of music plots, thus to obtain the general design technique and manifestation mode for music brochures.
\end{abstract}

Keywords-imagery creating; circumstance; musical symbol; auditory art; visual art; visual transformation

\section{INTRODUCTION}

Catalogue design is one of the important parts of the present commercial design, and the musical content catalogue can be seen often in music performance, musical hall annual plan introduction and other related activities scene. The approaches for brochure obtaining are posting by organization unit beforehand, picking up or buying on site or music hall and so on. In English "Catalogue" has meaning of contents, sample books, lists and so on ${ }^{1}$. From the view of essence, it belongs to the commercial propaganda and spreading media no matter which fields catalogues it is. The music catalogue mainly aims at the propaganda and spreading for musical fields with a kind of specific manifestation form.

The early catalogue design mainly purpose on clearly explanation, referring to the booking decoration forms. But by reason of the music's particularity, the plane forms are used to show the musicality and rhythm sensation, So the music catalogue start to step gradually into an era of imaginary creating from the entity image times. We can make brochures or program manual set off a better activity atmosphere by creating the proper musical circumstances.

\section{Music Catalogue Design “IMAgery CReating” INTRODUCING}

\section{A. Connotation of "Imagery Creating"}

"Imagery Creating" that is to say "Artistic Conception Creating", manifesting that the designer use his own imagination to make the visual content more suitable to deliver the required artistic conception space to get the audience moved by the music. In theory, the catalogue is free of any restriction, free design structure, to choose the format and paper sheet, thus presenting the ever-changing and swinging manifestation artistic conception ${ }^{3}$.

Artistic conception theory is the significant scope for Chinese traditional aesthetic ideology. As for the traditional paintings, the paints are the artistic state based on the intensive combination of feelings and scenery, using the description of space-time reflection. This artistic conception theory firstly appeared in the literary creation and criticism. In the era of three kingdoms, Jin dynasties, the northern and southern dynasties, there have the "Image" theory and the "Realm" theory. In Tang dynasty, the poet Wang Changling and Jiao Ran proposed the theory of "realm making" and "realm choosing", Liu Yuxi and the literary theory master Sikong Tu further proposed the creating understanding of "Image out of Images" and "Scenery out of Scenery". The music catalogue is to express human beings feelings' visual and non-visual content by different sounds to describe the practical living scenes, making audience falling into reverie. So this thesis is discussing to make the circumstance created by music into the visual imagery and getting audience rapidly falling into the imagery.

Music is the art of hearing. So the catalogue designers are required to create abundant artistic conception imagery to deliver the better music to audience, getting audience to experience the composers' emotion consciousness. The visual art and the auditory art are communicating art forms, they have commons and also differences, so the designers are required to understand and express them correctly.

\section{B. Music Catalogue Imagery Creating Mode}

Most of the music catalogues are the catalogue for concert, introduction for music activities, tickets for performance, records introduction and other propaganda presswork. All these press work have different forms and art images and different styles, and also the ever-changing technique for imagery creating.

But in general, the music catalogue could be divided into several categories as followings :

\section{1) Using the musical symbols to create the imagery}

Music symbols are the symbolic elements with music features. Symbol is the image with certain meaning. It could be the graphic image, characters combination, even the sounds 
signal, architecture modulation, and even it also could be a kind of ideology culture, a current event people. But in this thesis, the symbol is mainly the graphic image symbol, such as the high pitch symbol or low pitch symbol or pause symbol of the music score. The music is of sounds, while the image is without sounds, so based on the image's connecting function in mind, the music symbols design is used for pushing people into a created artistic conception space.

There are many different kinds of the music symbols, the modern numbered musical notation of Chinese score are mainly composed by figures and points, while in ancient dynasties, and there have had many different forms, such as Gongche notation and traditional musical notation and so on. The representative of the western musical score is the stave notations, many different kinds of symbols, and "tadpole type" musical symbols are the majorities and the lines assisting. No matter what kind of music, the notation itself can give a good visual effect by appearance, possessing the musical skipping affect to make people think of the music scenes. It shows that to add the musical symbols design into the music brochure is very easily lead audience to the "beautiful music hearing" circumstance. "Fig. 1", this is the brochure cover for foreign music propaganda, using the computer software to scatter the stave into pieces and then recombine them. During this recombination, some of the musical instruments are added and mixed with the stave symbols to making a colorful stereoscopic space in a brand-new visual expression language.

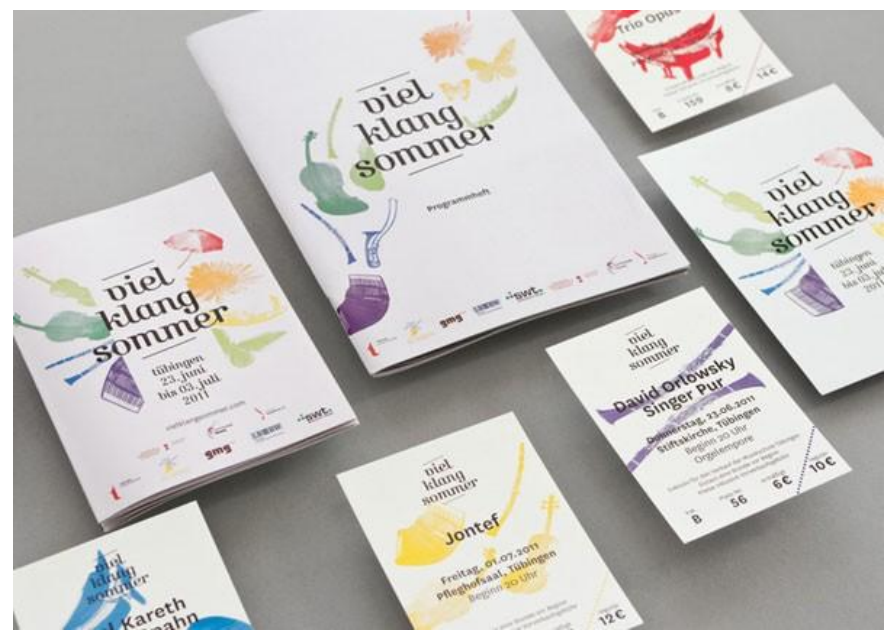

Fig. 1. Foreign music performance Brochure

The musical instrument symbol is another musical symbol for people's experience. Such as when people see the musical instrument pictures or parts of the instrument, people will think of the music naturally. If people have ever heard of this instrument's sounds, he will think of the beautiful sounds made by this instrument. "Fig. 2", it is the design for a foreign summer music festival performance propaganda. In this brochure, it is generally divided according to different categories, and different musical instruments in such a water color paint of various hues create the circumstance imagery with harmonic sounds of different instruments, meanwhile rich colors deliver an easy and happy musical atmosphere. From the picture, people will know it is not a serious classic music performance, but it is an easy, happy and comprehensive musical performance. And the name of brochure is printed on different sizes black blocks, like the floating of different musical symbols, helping the whole picture in rhythm and musicianship.

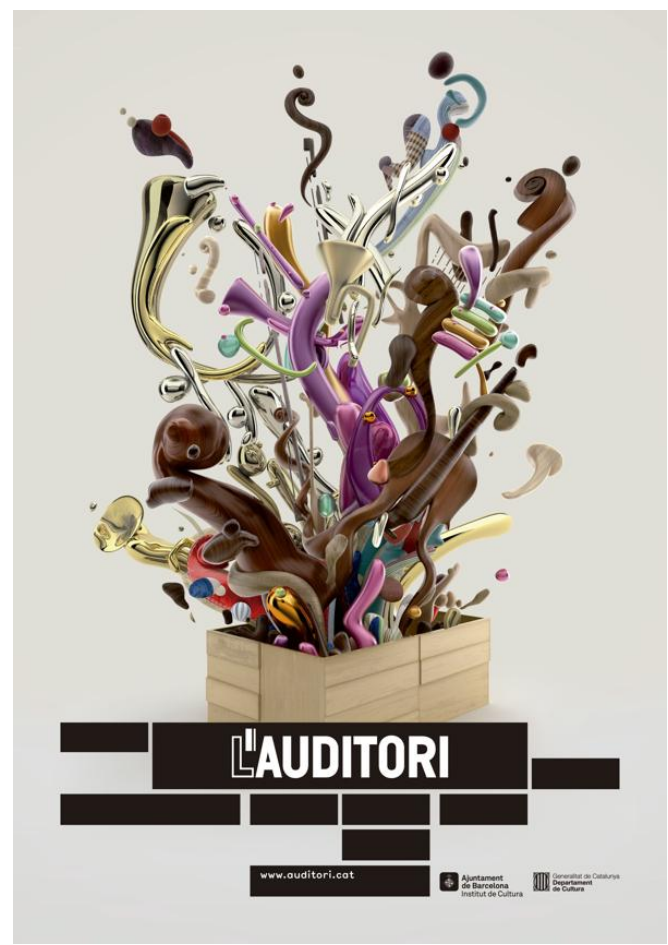

Fig. 2. The Design of the Foreign Music Brochure

\section{2) Imagery Creating based on the Musical Forms}

Musical form is a relative abstract concept. Music itself does not have visual image, only creating the auditory image, but there come up with a very vivid figurative visual image by hearing and mind connection.

In the music brochure, we can see the musical content was transformed into the visual image and arranged onto different pages, it is also a very common technique of expression. Certainly, some music can not be transformed into scenes and specific visual images for expression, the designer would use the musician image to express. During the performance, most of the musicians are immersed into the musical playing, their motions are floating with the musical beats changing, and also the facial expression and body gestures also change with the music's narrating. During the playing, musicians themselves have the responsibility to re-create the circumstance for audience. As for modern music brochure, such scenes are well recorded and applied, which is the common imagery creating technique. "Fig. 3", in this shanghai grand theatre 15 anniversary propaganda brochure, the designer adopt many photos of musical master alive performance, in the photos, the director and musician special body language and facial closeup expression, delivering directly to audience of the colorful musical circumstance. By intercepting of the performers' classical performance moment, using the picture overlaying, repeating, partial enlarged viewing and other processing 
technique to set off the atmosphere to its highest, realizing the artistic conception level that only sounds matters.

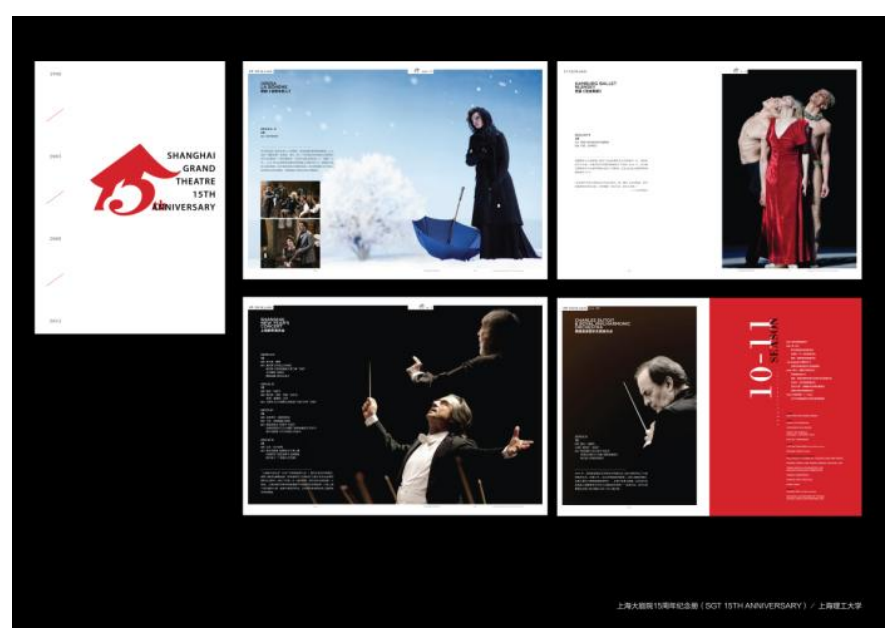

Fig. 3. 15 anniversary brochure of Shanghai grand theatre, designed by Wang Wei

\section{3) Imagery Creating based on the Musical Plots}

Lots of classical western and oriental music works are recorded in form of drama or opera, which are generated based on the stories in folks. During the performance, it will be divided into dance drama and musical drama under the actors acting. Most of the scenes are also very familiar by music fascinators. When such photos appeared in the brochure, audiences immediately understand the performance scene and music, realizing the purpose for imagery creating. The inside pages of the Tianjin grand theatre show season propaganda brochure. "Fig. 4", "Fig. 5"From these pages insides, we can find that each opera performance has its own targeted design and deliver the best performance scene to audience. Meanwhile, we can find the immersed actors "every twinkle and every smile" are changing with the performance and music, so audience also will be brought into the drama and opera plots. This is also the common design technique for musical story program propaganda brochure.

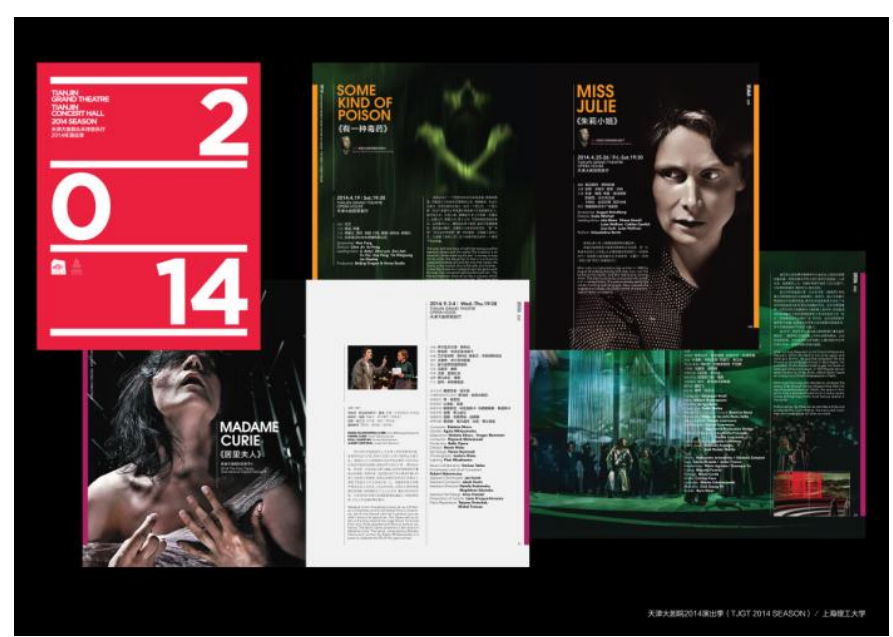

Fig. 4. Tianjin grand theatre show season brochure, designed by ang Wei

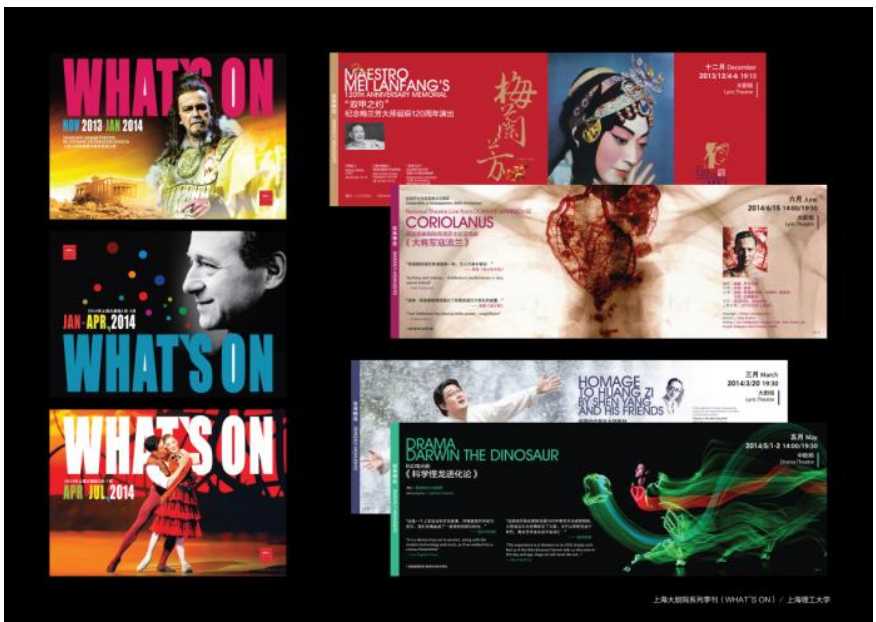

Fig. 5. Shanghai grand theatre propaganda brochure, designed by Wang Wei

\section{THE BEAUTY OF IMAGINARY CREATING FOR MUSIC BROCHURE.}

As the highest level of plane design, "Imaginary Creating" also can be treated as the highest pursuit of the non-visual product brochure. The pursuit is not only for certain page content, but also for the overall design from the content to format to materials. As for the overall imaginary creating mode, we could conduct from followings:

\section{A. Materials Beauty and Imagery Creating:}

Music catalogue is generated by the commercial propaganda and promotion of performance content, musical drama performance and musicians. Hence, every targeted object has its own characters and features. When the designer making the design, they pursuit not only the suitable elements combination from pages, but also the suitable page materials and stapling methods. If the stage scene is very wide and big, which can not emerged in the normal page, there a crossing edition even supplement pages to show it. So there need the special stapling method for making it. And there several photos could not reflect the metal materials itself color and natures under the normal shooting, so there need to use the spot-color painting and also "UV" special effects for metal materials to emphasize the visual impaction. So in order to achieving the imagery creating perfect effects, materials and stapling and designs arrangements all need considered during the whole process, realizing the effects unification.

To choose a suitable paper stapling is also a good method to reflect the auditory art materials, same as the graphics visual art, it is kind of technique for imagery creating. The Chinese ancient lyre and zither and also other traditional musical instruments, represent a unique musical form in china. In such musical performance, some of the designers use the Chinese traditional rice paper to publish the brochure, and also literal arrangement in vertical arrangement as the ancient books style, and the stapling method also imitating the organ pleats or as the ancient books stapling style. when people open this brochure, it seems to open a painting roll for the ancient lyre 
introduction. During the reading, people can feel the classical beauty which achieved by the designer. "Fig. 6"

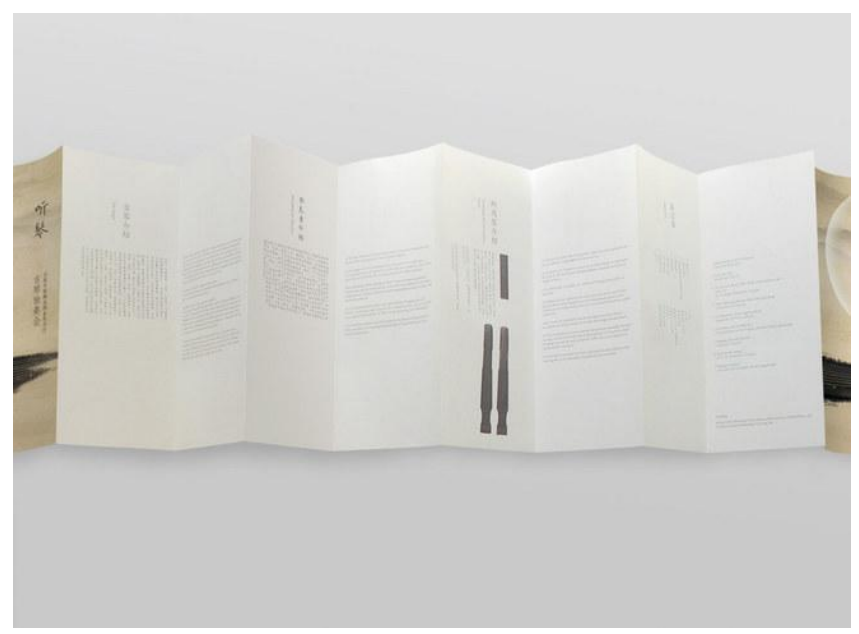

Fig. 6. The Introduction Manual for Chinese Ancient Lyre Perormance

\section{B. The Body and Spirit Unification for Creating the Multi- gradation Esthetic Experience}

Music is generated from auditory sense of human being' five senses and it is the art of "listening". And the visual designer should transform this art form into the art of "Looking". It has certain difficulty, so the designers need totally understand and experience this art form. Only the truly understanding of the art of "Listening", the art of "Looking" could be presenting correctly. It is the basic requirements for music brochures to transform people auditory sense into vision. The vision effect is set off to the suitable music by format, pictures, musical elements, colors and so on. Thus achieving the unity of form and spirit, leads people into the interesting part.

\section{CONCLUSION}

This thesis makes the research and summary on music catalogue to come up with many different imagery creating techniques. By these imagery creating forms and techniques, the modern music brochure design can leading audience to have a multi-gradation aesthetic experience. In this way, the designer and the audience can reach the intensive spiritual synchronization, promoting the fabulous musical circumstance creating to a higher visualization experience peculiarity.

\section{REFERENCES}

[1] "The application research of virtual space in commercial catalogue design" [M] Li Jinnan

[2] "The research on artistic conception of catalogue design " Peng Juan [J] Package Engineering

[3] "Catalog design of visual elements and integration" Liu Bin [ J ] Package Engineering

[4] "The social responsibility of catalogue design" Peng Juan [J] Journal of chongqing second normal college

[5] "The brief theory of general development situation of catalogue design and publishing "Meng Dan [J] Art and Literature for the Masses 